\title{
The Need to Give Calcium Supplementation after Total Thyroidectomy
}

\author{
Ahmed Magdy El-Haddad ${ }^{1, *}$ MBBch, Mohamed Salah Shehata ${ }^{2}$ MD and Ibrahim aboulfotoh Mohamed ${ }^{2}$ MD.
}

*Corresponding Author: Ahmed Magdy El-Haddad netttawy@gmail.com

Received for publication January 28 , 2020; Accepted July14, 2020; Published online July14, 2020.

Copyright 2020 The Authors published by Al-Azhar University, Faculty of Medicine, Cairo, Egypt. All rights reserved. This an openaccess article distributed under the legal terms, where it is permissible to download and share the work provided it is properly cited. The work cannot be changed in anyway or used commercially.

doi:10.21608/aimj.2020.22816.1114

${ }^{I}$ General Surgery Department, Oum Al-Masryeen General Hospital, Ministry of health.

${ }^{2}$ General Surgery Department, Faculty of Medicine, Al-Azhar University.

\begin{abstract}
Background: A prospective study was carried on female patients after total thyroidectomy to assess the need for calcium supplementation after surgery

Aim of the work: To assess the need for routine calcium supplementation after total thyroidectomy.

Patient and methods: From 2017 to 2018, a total of 90 female patients with different thyroid disorders were conducted. Thyroid cancer or previous neck surgery patients were excluded. Neck ultrasound was done.

Results: Study shows improvement in the level of serum calcium in the group already on supplementation. On the other hand it shows slight decrease in serum calcium level in the group without supplementation. The statistical analysis showed highly significant relationship between the $\mathrm{Ca}$ supplementation and hypocalcemia with $\mathrm{P}$ value of less than 0.05 . Conclusion: Certain risk factors are associated with post-thyroidectomy hypocalcemia. Total thyroidectomy, thyroiditis and routine non calcium supplementation are found to be the main risk factors of postthyroidectomy hypocalcemia in this study.
\end{abstract}

Keywords: calcium; thyroidectomy; hypo-calcemia; hypoparathyroidism; supplementation.

Disclosure: The authors have no financial interest to declare in relation to the content of this article. The Article Processing Charge was paid for by the authors.

Authorship: All authors have a substantial contribution to the article.

\section{INTRODUCTION}

Hypocalcemia may occur secondary to total thyroidectomy due to surgical trauma, devascularization, unintentional removal of parathyroid glands, and reoperation. Other causative mechanisms that have been implicated in the pathophysiology of post-thyroidectomy hypocalcaemia include calcium uptake by the bone in patients with thyrotoxicosteodystrophy, increased release of calcitonin as a result of thyroid manipulation. ${ }^{1}$

Postoperative hypocalcaemia is more common after total thyroidectomy than after other types of thyroidectomies. ${ }^{2}$ It usually manifests itself in the first 24 hours post operatively or within the 2-3days after operation, however, very rarely the onset is delayed 2-3 weeks. ${ }^{3}$ Hypocalcemia may be transient, resolving within a few months, or permanent, requiring lifelong oral calcium and vitamin $\mathrm{D}$ supplementation. ${ }^{4}$ In most patients it is transient that resolves spontaneously and only few patients develop permanent hypocalcaemia. $^{5}$

Serum calcium is distributed among three forms (protein bound $40 \%$, complexed to phosphate and other anions $10 \%$ and ionized $50 \%{ }^{6}$ The first clinical sign of hypocalcaemia may be less typical and may include numbness and tingling sensation around the mouth and extremities. ${ }^{7}$ Tetany, which is characterized by carpopedal spasm, laryngeal stridor and tonic-clonic seizures may occur. ${ }^{6}$

Intravenous calcium gluconate should be given 10-20 $\mathrm{ml}$ of $10 \%$ solution slowly until the symptoms disappear, then $50 \mathrm{ml}$ of $10 \%$ calcium gluconate can be added to $500 \mathrm{ml}$ of $5 \%$ dextrose solution and administered by intravenous drip at a rate of 1 $\mathrm{ml} / \mathrm{kg} / \mathrm{h} .{ }^{8}$ Routine oral calcium and vitamin D supplements have been proposed to prevent the development of symptomatic hypocalcemia and to increase the likelihood of early hospital discharge after bilateral surgical treatment of the thyroid gland9. ${ }^{8}$

\section{PATIENT AND METHODS}

Accepted patients had been diagnosed as different thyroid diseases other than cancer and had bilateral total thyroidectomy done. Patients enrolled were females with no limitation for age. Acceptance also included within normal renal and hepatic profile and adequate thyroid profile. Patients were excluded if parathyroid mass was found during total thyroidectomy or thyroid cancer; previous neck surgery or radiation therapy; or prior calcium and/or vitamin D intake.

This prospective study was carried on 90 patients who had total thyroidectomy surgery done for various thyroid diseases at the department of surgery 
-Oum Al Masryeen General Hospital and Al-Azhar University Hospitals in the period between 2017 2020. The study protocol was approved by the Ethical committee and an informed consent was taken from every patient.Accepted participants were assigned in a random way in a 1:1 ratio to receive calcium and vitamin D (routine calcium supplemented group) or without supplementation (control group).

The present study main end point is to evaluate the need to give routine calcium supplements postoperatively to patients who had done total thyroidectomy, as assessed by the occurrence of symptomatic hypocalcemia for 3 months after surgery.

Patients in the routine calcium group received oral calcium and vit D supplementations from first postoperative day for two weeks, whereas patients received no supplementation in the control group. Serum calcium levels were followed up in the postoperative period for three months. If symptomatic hypocalcemia occured in any of the two groups intravenous calcium tobe given followed by oral calcium supplements.

Analysis of data was done by IBM computer using SPSS (statistical program for social science version 21) as follows:

\begin{tabular}{|c|c|c|c|}
\hline AGE & With Ca supplement & Without Ca supplement & P value \\
\hline Mean \pm SD & $42.73 \pm 15.75$ & $48.13 \pm 13.76$ & \multirow{2}{*}{0.223} \\
\hline Median (IQR) & $37(29: 59)$ & $45(40: 52)$ & \\
\hline
\end{tabular}

Table 1: Shows age in relation to need of calcium supplementation and its statistical insignificance.

The majority of patients $(69,76.66 \%)$ had multinodular goiter. On the other hand only 21 patients with percentage $23.33 \%$ had other thyroid pathologies including Hashimoto's thyroiditis and
Description of quantitative variables as mean, SD and median and IQR.Description of qualitative variables as number and percentage. We used Chisquare test to compare qualitative variables between groups. Fisher exact test was used instead when one expected cells are less than 5. MannWhitneytest was used instead of unpaired t-test in non-parametric data (SD>30\%mean). Wilcoxontestusedtest was used instead of paired t-test in non-parametric data (SD $>30 \%$ mean). $\quad \mathrm{P} \leq 0.05$ significant and $\mathrm{P}<0.01$ highly significant.

This study included 90 patients who underwent total thyroidectomy due to different thyroid diseases. The preoperative serum calcium level was measured and was found to be normal in all cases. The postoperative serum calcium was measured three months postoperative.

\section{RESULTS}

The present study includes 90 patients with ages range from 21 to 84 divided into two groups based on whether they were on calcium supplementation or not. $100 \%$ of patients were females. There was no statistical significance of age in relation to serum $\mathrm{Ca}$ level as $\mathrm{P}$ value $>0.05$ (Table 1).

\begin{tabular}{|l|c|c|c|c|c|}
\cline { 2 - 5 } \multicolumn{1}{c|}{} & \multicolumn{2}{c|}{ Ca with supplement } & \multicolumn{2}{c|}{ Ca without supplement } & \multirow{2}{*}{ P value } \\
\cline { 2 - 5 } \multicolumn{1}{c|}{} & $\mathrm{N}$ & $(\%)$ & $\mathrm{N}$ & $(\%)$ & \multirow{2}{*}{0.39} \\
\hline Nodular adenomatous G & 30 & $(66.7)$ & 39 & $39(86.7)$ & $2(13.3)$ \\
\hline Other pathologies & 15 & $(33.3)$ & 6 & \\
\hline
\end{tabular}

Table 2: Shows number and percentage of patients with different clinic-pathological diagnosis and its insignificance to serum calcium post-operative.

The time needed for total thyroidectomy in both groups which is almost the same. This means there's no statistical significance of relation between time

consumed in surgery and serum $\mathrm{Ca}$ level with $\mathrm{P}$ value $>0.05$ (Table 3 )

\begin{tabular}{|c|c|c|c|}
\hline Time of Surgery & Ca with supplement & Ca without supplement & P value \\
\hline Mean \pm SD & $1.6 \pm 0.51$ & $1.57 \pm 0.56$ & \multirow{2}{*}{0.838} \\
\hline Median (IQR) & $1.5(1: 2)$ & $1.5(1: 2)$ & \\
\hline
\end{tabular}

Table 3: Shows the Relation between the Time of surgery in both groups and its insignificance to serum calcium post-operative.

Study shows improvement in the level of serum calcium in the group already on supplementation. On the other hand it shows slight decrease in serum calcium level in the group without supplementation.
The statistical analysis showed highly significant relationship between the $\mathrm{Ca}$ supplementation and hypocalcemia with $\mathrm{P}$ value of less than 0.05 ; that serum calcium level post-operative in the routine 
calcium group demonstrate increase in the serum level of calcium with Mean \pm SD (8.51 \pm 0.33$)$. On the other hand serum calcium level post-operative in the control group demonstrate decrease in the serum level of calcium with Mean \pm SD $(6.88 \pm 0.92)$ (Figures 1,2) (Tables 4-6).

\begin{tabular}{|l|c|c|c|}
\hline F.U Ca in both groups & with Ca supplement & without Ca supplement & P value \\
\hline Mean \pm SD & $8.51 \pm 0.33$ & $6.88 \pm 0.92$ & $<0.001$ \\
\hline Median (IQR) & $8.4(8.3: 8.6)$ & $7.2(6.7: 7.4)$ & \\
\hline
\end{tabular}

Table 4: Shows the significant relation between follow-up serum Ca levels in both groups.

\begin{tabular}{|l|c|c|c|}
\hline Ca with supplement & Preoperative Ca & Follow up Ca & P value \\
\hline Mean \pm SD & $8.2 \pm 0.4$ & $8.5 \pm 0.3$ & \multirow{2}{*}{0.001} \\
\hline Median(IQR) & $8.1(8: 8.5)$ & $8.4(8.3: 8.6)$ & \\
\hline
\end{tabular}

Table 5: Shows the significant relation between calcium supplementation and increase in Ca serum levels postoperatively.

\begin{tabular}{|c|c|c|c|}
\hline Ca without supplement & preoperative Ca & Follow up Ca & P value \\
\hline Mean \pm SD & $8.15 \pm 0.41$ & $6.88 \pm 0.92$ & \multirow{2}{*}{0.001} \\
\hline Median (IQR) & $8.2(8: 8.4)$ & $7.2(6.7: 7.4)$ & \\
\hline
\end{tabular}

Table 6: Shows the significant relation between Non calcium supplementation and decrease in Ca serum levels post-operatively.

The majority of patients in both groups are not hypertensive with percentage $(73.3 \%)$ while the percentage of patients with hypertension and/or IHD ranges from (20-26.7\%). This statistical analysis is not significant as $\mathrm{P}$ value $>0.05$. Also the majority of patients in both groups are not diabetics with percentage $(80 \%)$ while the percentage of patients with Diabetes $(20 \%)$. This statistical analysis is not significant as $\mathrm{P}$ value $>0.05$. Socollectively no significant relationship between diabetes and hypertension to postoperative hypocalcemia (Tables 7-8).

\begin{tabular}{|c|c|c|c|c|c|}
\cline { 2 - 5 } \multicolumn{1}{c|}{} & \multicolumn{2}{c|}{ Ca with supplement } & \multicolumn{2}{c|}{ Ca without supplement } & P value \\
\hline Hypertension & $\mathrm{N}$ & $(\%)$ & $\mathrm{N}$ & $\mathrm{N}(\%)$ & \\
\hline Nill & 33 & $(73.3)$ & 33 & $(73.3)$ & \multirow{2}{*}{0.595} \\
\hline HTN & 12 & $(26.7)$ & 9 & $(20)$ & $(6.7)$ \\
\hline HTN \& IHD & 0 & $(0)$ & 3 & \\
\hline
\end{tabular}

Table 7: Shows the insignificant relation of Hypertension and IHD in both groups to post-operative hypocalcemia.

\begin{tabular}{|c|c|c|c|c|c|}
\cline { 2 - 5 } \multicolumn{1}{c|}{} & \multicolumn{2}{c|}{ Ca with supplement } & \multicolumn{2}{c|}{ Ca without supplement } & P value \\
\hline Diabetes & $\mathrm{N}$ & $(\%)$ & $\mathrm{N}$ & $(\%)$ & \\
\hline Nil & 36 & $(80)$ & 36 & $(80)$ & \multirow{2}{*}{1} \\
\hline DM & 9 & $(20)$ & 9 & $(20)$ & \\
\hline
\end{tabular}

Table 8: shows the insignificant relation of Diabetes in both groups to post-operative hypocalcemia.

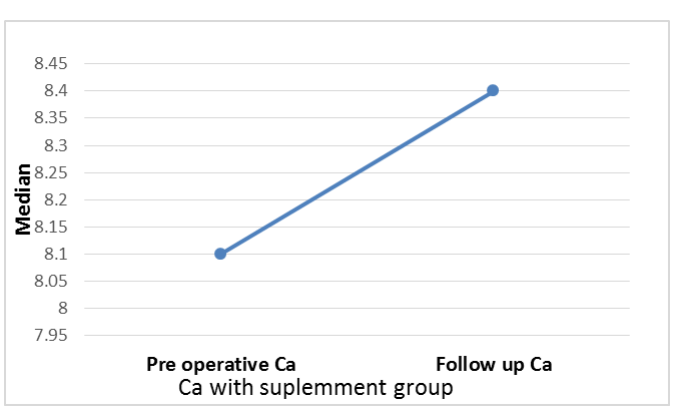

Fig. 1: Relation between $\mathrm{Ca}$ supplementation and post-op serum $\mathrm{Ca}$ denoting increase in the serum level of calcium with Mean \pm SD $(8.51 \pm 0.33)$. The statistical Analysis of the relation between $\mathrm{Ca}$ supplementation and post-operative serum $\mathrm{Ca}$ is highly significant as the $\mathrm{P}$ value $<0.05$. 


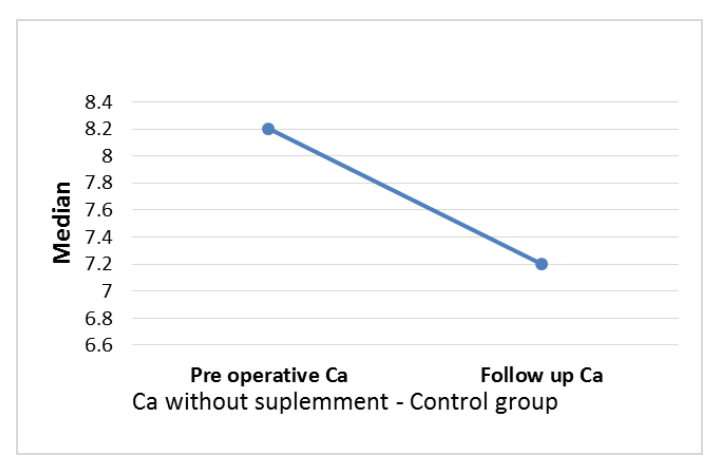

Fig. 2: Relation between Non Ca supplementation and post-op serum $\mathrm{Ca}$ denoting decrease in the serum level of calcium with Mean \pm SD $(6.88 \pm 0.92)$. The statistical Analysis of the relation between Non Ca supplementation and post-operative serum $\mathrm{Ca}$ is highly significant as the $\mathrm{P}$ value $<0.05$.

\section{DISCUSSION}

Hypocalcemia is the most common complication of total thyroidectomy. It is important to identify and avoid high-risk surgical techniques to lower the rate of this complication. ${ }^{9,10}$ Early symptomatic hypocalcemia is the most recurrent complication after thyroid surgery. Several studies have identified factors (Patient characteristics or variations in surgical technique) affecting hypocalcemia following total thyroidectomy. ${ }^{11}$

Transient hypocalcemia is a common disorder that occurred after thyroid surgery, which is defined as decrease the calcium level below the normal during hospital stay and or recovery within 3 months. ${ }^{12,13}$

Some authors concluded that PTH at one hour after thyroid resection whether a partial/subtotal thyroidectomy procedure has a predictive power of $94.4 \%$, respective a specificity of $83.6 \%$ with a positive value of prediction of $53 \%$, and a negative value of prediction of $98.7 \% .^{14}$ Moreover, a combination of PTH and calcium assay might be of more accuracy to indicate the need for replacement of calcium, for instance a value of intact PTH one hour post-operative of higher than $10 \mathrm{pg} / \mathrm{mL}$ and a total calcium level of higher than $8.5 \mathrm{mg} / \mathrm{dL}$ makes calcium replacement unnecessary. ${ }^{15}$ However the PTH predictive values is marked by two practical aspects: one is represented by the costs associated with assaying PTH as a blood test marker and the another is related to the controversies around the best timing for PTH assessment. ${ }^{16}$

In our study 90 female patient who had total thyroidectomy done for different thyroid disorders and had been grouped into two groups based on whether they get routine $\mathrm{Ca}$ supplementation or not after surgery. The group without $\mathrm{Ca}$ supplementation expressed a decreased serum $\mathrm{Ca}$ level post-operative of Mean \pm SD $(6.88 \pm 0.92)$ and $\mathrm{P}$ value $=0.001$ which is highly significant and also meet the corresponding results in different studies like. ${ }^{17}$

This study shows that routine post-operative $\mathrm{Ca}$ supplementations significantly decreased the rate of post-operative hypocalcemia with serum level of calcium of Mean \pm SD $(8.51 \pm 0.33)$ and $\mathrm{P}$ value < 0.05 which correspond to results of many studies like. $^{18}$

Previous studies have reported conflicting results regarding the association of age with the risk of hypocalcemia, but a meta-analysis showed that there is no significant difference in the mean age between patients with and without transient hypocalcemia. ${ }^{19,20}$

Menopause may negatively affect absorption of intestinal calcium, which favors the risk of postoperative hypocalcemia. However, as older age might be associated with menopause in women, the association using multivariate logistic regression model was investigated. After confounders being adjusted, no association between menopause and postoperative symptomatic hypocalcemia were found. Other researchers also stated that the incidence of transient hypoparathyroidism and PTH levels were comparable between pre-menopausal and postmenopausal women. ${ }^{21}$ Khosla et al., further demonstrated that no association between serum PTH level and menopausal status. Therefore, menopause might have no effect on the PTH level after surgery.

In our study there was no statistical significance in the relation between age and post-operative hypocalcemia which corresponds to results in many studies like. ${ }^{10}$

Although our study only included samples of female gender, several other studies showed that the female patients are at a two-fold higher risk of developing transient hypocalcemia compared to men. ${ }^{22}$

In our study there was no statistical evidence that different thyroid pathologies could affect postoperative $\mathrm{Ca}$ level however, other studies stated that the highest incidence of post-operative hypocalcemia was found in patient diagnosed as thyroid cancer, followed by toxic goiter and then multinodular goiter. $^{2}$

Although neither of our cases was diagnosed as toxic goiter but toxic goiter is a risk factor of hypocalcemia after thyroid surgery is due to extensive adhesions between thyroid capsule and parathyroid glands in Graves' disease, which leads to their injury and subsequently hypocalcemia. ${ }^{23}$ Hungry bone syndrome is another cause ofhypocalcemia in thyrotoxic cases after thyroidectomy due to increase in excretion of calcium in urine and osteodystrophy with increase in osteoclast activity and impaired of mineralization of bone. After thyroidectomy increased mineralization of bone leads to rapid recalcification and hypocalcemia due to loss of stimulation by hormones of thyroid. ${ }^{24}$

Total thyroidectomy had the highest percentage of post-thyroidectomy hypocalcemia due to bilateral ligation of inferior thyroid artery and posterior capsule removal of thyroid gland with risk of parathyroid gland injury ${ }^{25}$,also congestion and edema of parathyroid glands due to dissection andisolation 
of recurrent laryngeal nerve and ligation of inferior thyroid veins leads to slow parathyroid function and temporary hypocalcemia. Intracapsular dissection technique is used to decrease incidence of hypocalcemia with individual ligation of the tertiary branches of inferior thyroid artery in the thyroid capsule to avoid injury to vessels of parathyroid glands. ${ }^{26-27}$

Parathyroid glands preservation is achieved by their identification and ligation of inferior thyroid artery branches distal to the glands. Parathyroid glands have a caramel like color, which darken in appearance when they lose their blood supply. ${ }^{28}$

Routine vitamin D and low-dose calcium supplements after surgery did not reduce the risk of postoperative hypocalcemia. Patients who may benefit from calcium and/or vitamin D replacement should be selected carefully.

Previous meta-analyses demonstrated a significant decrease in symptomatic hypocalcaemia with less severe symptoms when calcium + vitamin D3 is routinely administered. ${ }^{17}$

It should be asserted that good surgical technique with parathyroid glands preservation is the best approach to prevent postoperative hypocalcaemia.

\section{CONCLUSION}

Certain risk factors are associated with postthyroidectomy hypocalcemia. Total thyroidectomy, thyroiditis and routine non calcium supplementation were found to be the main risk factors of postthyroidectomy hypocalcemia in the present study.

\section{REFERENCES}

1. Güllüoglu B, Manukyan M, Cingi A, et al. Early prediction of normocalcemia after thyroid surgery. World J. Surg., 2005; 29 (10): 1288-93.

2. Shaaeli A. The incidence and risk factors of hypocalcaemia in post thyroidectomy patients, prospective study at Al-Hilla Teaching hospital. Int. J. Med. Phar. Sci., 2015; 5:8.

3. Krukowski Z. The thyroid gland and thyroglossal tract. Baily and love's short practice of surgery. London, 2005.

4. Baldassarre $\mathrm{R}$, Chang $\mathrm{D}$, Brumund $\mathrm{K}$, et al. Predictors of hypocalcemia after thyroidectomy: results from the nationwide inpatient sample. ISRN Surgery, 2012.

5. Walling A. Calcium and Vitamin D Prevent Hypocalcemia After Thyroidectomy. American Family Physician, 2007; 75 (6): 910-912.

6. Ganong W and Barrett K. Review of medical physiology: McGraw-Hill Medical New York, 2005.
7. Fauci A. Harrison's principles of internal medicine: McGraw-Hill Medical New York; 2008.

8. Way L and Doherty G. Current surgical diagnosis and treatment. McGraw-Hill Companies. Inc, USA. 2003.

9. Bellantone R, Lombardi C, Raffaelli M, Boscherini M. Is routine supplementation therapy (calcium and vitamin D) useful after total thyroidectomy? Surgery, 2002; 132:110912 .

10. Khazaeni K, Mousavi V. Surgical and Clinical Risk Factors of Postoperative Hypocalcemia after Total Thyroidectomy. Am J Otolaryngol Head Neck Surg. 2019; 2(1): 1031.

11. Khosla S, Atkinson EJ, Melton LJ,et al.. Effects of age and estrogen status on serum parathyroid hormonelevels and biochemical markers of bone turnover in women: apopulation-based study. $J$ ClinEndocrinolMetab1997;82:1522-7.

12. Del Rio P., Rossini M., Montana C.M. et al. Postoperative hypocalcemia: analysis of factors influencing early hypocalcemia development following thyroid surgery. $B M C$ Surg 2019; 18, 25.

doi:10.1186/s12893-019-0483-y

13. Sakorafas G, Stafyla V, Bramis C, Kotsifopoulos $\mathrm{N}$. Incidental para-thyroidectomy during thyroid surgery: an underappreciated complication of thyroidectomy. World J Surg. 2005; 29 (12):1539-43

14. Shiryazdi S, Kargar S, Afkhami-Ardekani M, et al. Risk of Postoperative Hypocalcemia in Patients Underwent Total Thyroidectomy, Subtotal Thyroidectomy and Lobectomy Surgeries. ActaMedicaIranica, 2014; 52 (3): 2069.

15. Rosario PW andCalsolari MR. Usefulness of Serum Calcitonin in Patients Without a Suspicious History of Medullary Thyroid Carcinoma and with Thyroid Nodules Without an Indication for Fine-Needle Aspiration or with Benign Cytology. HormMetab Res. 2016;48(6):276-372.

16. Sanabria A and Kowalski LP, Tartaglia F. Inferior thyroid artery ligation increases hypocalcemia after thyroidectomy: A metaanalysis. Laryngoscope. 2018;128(2):534-41.

17. Sanabria A, Dominguez LC, Vega V, et al. Routine postoperative administration of vitamin $\mathrm{D}$ and calcium after total thyroidectomy: a metaanalysis. Int J Surg 2019; 9: 46-51. 
18. Xing, T., Hu, Y., Wang, B., et al. Role of oral calcium supplementation alone or with vitamin $\mathrm{D}$ in preventing post-thyroidectomy hypocalcaemia. Medicine, 2019; 98(8), e14455.

19. Edafe O, Prasad P, Harrison B, et al. Incidence and predictors of post-thyroidectomy hypocalcaemia in a tertiary endocrine surgical unite. Ann R CollSurgEngl, 2014; 96: 219-23.

20. Edafe O, Antakia R, Laskar N, et al. Systematic review and meta-analysis of predictors of postthyroidectomy hypocalcaemia. $\mathrm{Br} \quad J$ Surg. 2014;101(4):307-20.

21. Sands N, Payne R, Côté V, et al. Female Gender as a Risk Factor for Transient PostThyroidectomy Hypocalcemia. American Academy of Otolaryngology-Head and NeckSurgery Foundation, 2011; 145(4) 561-4.

22. Luo H, Yang H, Zhao W, et al. Hypomagnesemia predicts postoperative biochemical hypocalcemia after thyroidectomy. BMC Surg. 2017;17(1):62.

23. Karamanakos S, Markou K, Panagopoulos K, et al. Complications and risk factors related to the extent of surgery in thyroidectomy. Results from 2,043 procedures. HORMONES 2010; 9 (4): 318 25.

24. Sousa A, Salles J, Soares J, et al.Predictors factors for post-thyroidectomy hypocalcemia. Rev. Col. Bras. Cir, 2012; 39(6): 476-82.

25. Testini M, Rosato L, Avenia N, et al.The impact of single parathyroid gland autotransplantation duringthyroid surgery on postoperative hypoparathyroidism: a multicenter study.Transplant Proc 2007; 39: 225-30.

26. kalyoncu D, Gönüllü D, Gedik M, et al. Analysis of the factors that have an effect on hypocalcemia following thyroidectomy. Turkish Surgical Association, UlusalCerDerg., 2013; 29: 171-6.

27. Rageh T, El Gammal A, Elsisi A, et al. Intracapsular total thyroidectomy; no more complications in benign thyroid diseases. The Egyptian journal of surgery, Wolters KluwerMedknow,2016; 35:445-8.

28. Ozbas S, kocak S, Aydintug S, et al. Comparison of the complications of subtotal, near total and total thyroidectomy in the surgical management of multinodular goiter.Endocr. J. 2005; 56 (2): $199-202$. 